\title{
Midwives and pregnant men: labouring toward ethical care in the United States
}

\author{
— Cite as: CMAJ 2020 February 18;192:E169-70. doi: 10.1503/cmaj.190959
}

$\mathrm{n}$ recent years, midwives have expanded their scope of practice to include transgender men; that is, men assigned female at birth who have transitioned. Transgender men may still have female reproductive organs and be able to conceive, carry a pregnancy and give birth. Midwives have been mostly supportive of their transgender clients, including curricular units on transgender affirmative hormone care in their training, for example, and shifting the language of their documents from "mothers" and "women" to gender-neutral words, such as "pregnant people," "patients" or "families." But in the United States, these changes have not come without controversy. Some midwives (and others) believe that pregnancy and childbirth should remain "women's space," and see no reason to accommodate trans or nonbinary pregnant patients. Others are willing to open their practices but face constraining state licensure laws, which have conventionally restricted midwifery care to women only (ob-gyns in the US have only recently been allowed to expand their client base to include men ${ }^{1}$ ). Midwives and patients who seek changes face cultural as well as legal and medical obstacles. I put today's controversies in historical context, tracing bitter disputes regarding various meanings and ideals of womanhood, motherhood and feminism and highlight a central tension in the contemporary construction of "gender dysphoria."

Transgender pregnancies expose a fraught consensus regarding the rigidity of transitioning from one gender to another. After all, what could be more "womanly" than giving birth? And yet, there are men who want to do just that. Pregnant men should prompt us to re-evaluate what we

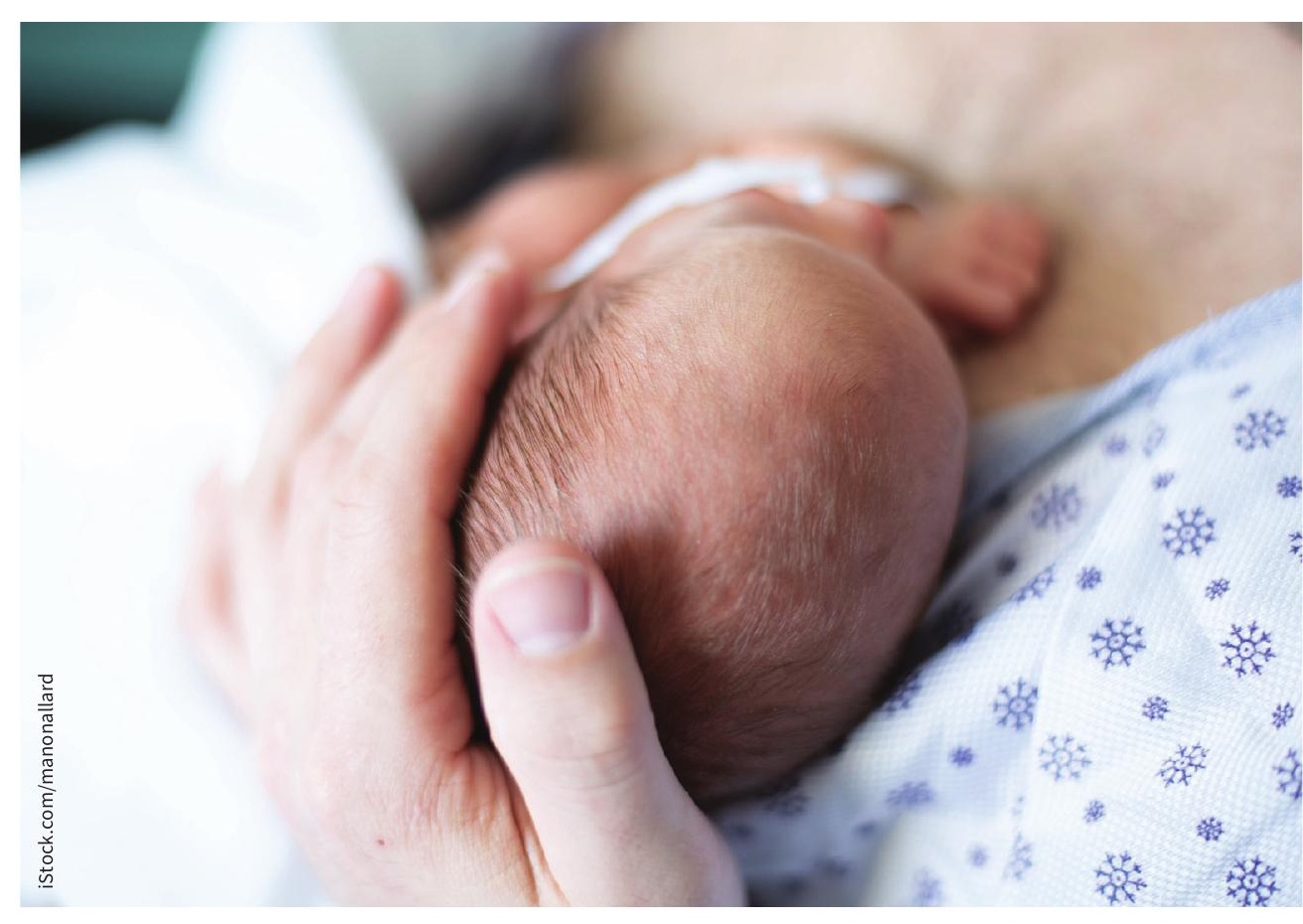

think we know about the presumed stability of the male-female binary at the same time that their predicament should open our hearts to the needs of vulnerable patients who deserve compassionate care.

A firestorm erupted in 2014 when the Midwives Alliance of North America (MANA) - a professional organization organized in 1982 by Ina May Gaskin issued a statement supporting the care of transgender patients, which included altering some of the language in its core competencies document. There was a swift and emotional response. A group called Women-Centered Midwifery, led by Mary Lou Singleton, a long-time midwife and former MANA member, penned an "Open Letter" to the organization, accompanied by more than 200 signatures of midwives, doulas, nurses and women who just signed "mother," decrying the revisions. Although they appreciated MANA's attempts at inclusivity, they disagreed vehemently with the very premise that men could give birth. These are "female-bodied people," not "men," they insisted. MANA should not prioritize gender identity over biology; nor should it delete the word "woman" from its documents. They believed that changing sex was impossible, and so transgender men were "really" women pretending to be men. From this perspective, why should language be transformed to accommodate what they saw as the spurious needs of imposters? ? $^{2,3}$

The question of who qualifies as a "real" woman or man was not new. Janice Raymond's inflammatory book, The Transsexual Empire: The Making of the She-Male, first published in 1979, articulated many 
of the antitransgender attitudes that circulate in today's discussions among midwives resistant to these changes. Raymond argued starkly that no matter what hormonal or surgical intervention trans people imposed on their bodies, they remained the sex they were assigned at birth. Focusing on trans women in particular - or, as she derisively called them, "male-to-constructed females" Raymond claimed that transsexual surgery was just one more way that men could enact patriarchal control of women. Undergoing what was then called "sexchange surgery," according to Raymond, "points to the general accessibility of women, this time with men acquiring the female body not only as sexual and/or reproductive property, but through hormonal and surgical construction." ${ }^{4}$ The idea that men were trying to take over women's bodies and women's spaces lingered and even today looms over the debate regarding midwifery and pregnant transgender men. ${ }^{4}$

For their part, transgender men have explained that they are not trying to take over women's bodies. "It is possible," according to Trevor MacDonald, trans parent and author, "to be inclusive of diverse gender identities and celebrate the power of the female body." MacDonald entirely agreed that women have been subjugated by a patriarchal society and have given birth under oppressive circumstances where they've lacked control over their own bodies. So, too, he argued, have gender-nonconforming and trans people. And that can change. ${ }^{6}$

Until recently, most physicians assumed that if people wanted to change their gender, then they also wanted to distance themselves from all things typically associated with that gender, particularly pregnancy. And indeed, since the late-twentieth century, transgender people have learned the required script to convince authorities to approve genderaffirmation surgery. Telling the physician or therapist that they did not want to be parents or get pregnant would likely have made their case for surgery more compelling. Saying the right thing to authorities does not make trans people duplicitous, but rather reflects the difficult circumstances that constrained them; and in many cases, there can be no doubt that such statements truly expressed their thinking. ${ }^{7}$ Sometimes the choice wasn't theirs to make. Until recently, in Sweden, the requirements for getting surgery included prior sterilization, a regulation that remained in effect from 1972 to 2013, when trans people and others lobbied to change the law. ${ }^{8}$

There are no reliable statistics on how many transgender men have given birth. But it is likely that the relatively low numbers will increase, as virtually all primary centres caring for trans patients provide information on fertility preservation. ${ }^{9}$ Of course, not all transgender men want to go through pregnancy and birth. However, others surprise themselves when they realize they want to have this experience.

Trystan Reese, a trans man who has written extensively about his own pregnancy, argues that in order to understand pregnant men, we have to abandon our previous assumptions about trans people. They don't uniformly believe that they were born in the wrong bodies; nor do they all hate their bodies. Reese lives as a man but writes, "I'm OK with my body being a trans body. I'm OK being a man who has a uterus and has the capacity and capability of carrying a baby." ${ }^{10}$

Gender politics aside, given these new realities, it is important for health care providers to understand the biology of transgender men's bodies because the interventions that produce such transitions can alter them physically in ways that distinguish them from cisgender women. ${ }^{11}$ Providers should know the dosage, routes of administration, and possible risks and adverse effects of exogenous testosterone or other gender-affirming hormone therapy, for example. If trans or nonbinary patients have had chest surgery but want to nurse their baby using a supplemental nursing system, they might need additional lactation consultation. And that's just the physical part. Transgender men should also be able to count on emotional support, and consult providers who appreciate the challenges of nontraditional birthing and parenting. ${ }^{12}$ All people - even men having babies - deserve competent and sensitive health care.

\section{Elizabeth Reis PhD}

Macaulay Honors College, City University of New York, New York, NY

\section{References}

1. Grady D. Gynecologists may treat men, board says in switch. The New York Times 2013 Nov. 26.

2. Singleton M, San Buenaventura Peixinho M, Cook $\mathrm{K}$, et al. Open Letter to MANA [Midwives Alliance of North America]. 2015 Aug. 20. Available: https://womancenteredmidwifery.wordpress.com /take-action/ (accessed 2019 July 22).

3. Kali K, Carter A, Ruby A, et al. Response to the open letter to MANA. Birthforeverybody.org. Available: www.birthforeverybody.org/response -to-open-letter (accessed 2019 Sept. 26).

4. Raymond J. The transsexual empire: the making of the she-male. New York: Teachers College Press; 1994.

5. MacDonald T. Transphobia in the midwifery community [blog]. Huffpost 2015 Sept. 15.

6. Graham N. Meet the trans midwife changing the world's "most gendered profession." The Stranger [Slog] 2019 Jan. 8.

7. Meyerowitz J. How sex changed: a history of transsexuality in the United States. Cambridge: Harvard University Press; 2002:130-67.

8. Löfgren E. "Historic decision": Sweden to offer payouts to sterilized transsexuals. The Local 2018 Mar. 22.

9. Amato P. Fertility options for transgender persons. San Francisco: University of California San Francisco, Center for Excellence for Transgender Health; 2016. Available: http://transhealth.ucsf. edu/trans?page=guidelines-fertility (accessed 2019 July 22).

10. Coleman N. Transgender man gives birth to a boy. CNN 2017 Aug. 1.

11. Toze M. The risky womb and the unthinkability of the pregnant man: addressing trans masculine hysterectomy. Fem Psychol 2018;28:194-211.

12. Ellis SA, Wojnar DM, Pattinato M. Conception, pregnancy, and birth experiences of male and gender variant gestational parents: it's how we could have a family. J Midwifery Womens Health 2015;60:62-9.

This article has been peer reviewed.

Competing interests: None declared. 